\title{
MANIFESTACIÓN DE DINEROS EN LA ADUANA DE MURCIA (1493-1494)
}

\author{
Juan Torres Fontes
}

Fuente de conocimiento histórico no abundante y que pocas veces ha atraído la atención de los investigadores es la obligación que todo viajero, cualquiera que fuera su procedencia, condición social y dirección de marcha, debía efectuar a su paso por la aduana de cada reino peninsular, manifestando cuánto llevaba consigo. Éste era el modo de evitar la confiscación de las cosas que estaba prohibido exportar o introducir en el Reino, así como su control y filtro aduanero y de los alcaldes de sacas, vigilantes destinados a evitar fraudes, contrabando o infracciones, y lugar en dónde debía pagarse el diezmo del almojarifazgo.

Cuando en el siglo XIII las fronteras de los reinos peninsulares se fijan y estabilizan, la organización de la Monarquía se perfecciona y extiende su poder inquisitivo y fiscal con mayor precisión y acorde con las cada vez mayores necesidades y conveniencias de la Corona y hacienda regia. Se supera el viejo sistema de vigilancia y arancel en los puertos secos o marítimos de carácter señorial o concejil, para llevar a cabo un mayor control e inspección de las fronteras de cada uno de los reinos que se integran en la Corona castellana. Se intenta acabar con la excesiva libertad de movimiento que tenían los sacadores o contrabandistas; se exige seguir el camino real y no salir de él, so pena de perder cuanto llevara por descaminado; pagar el diezmo del almojarifazgo y presentar documento justificativo que autorizara la saca de objetos, moneda o animales cuya exportación estaba prohibida; se proporcionan facilidades a los mercaderes para depositar sus fardos en la aduana y se relaciona su contenido cuando son abiertos. Más tarde, esta vigilancia político-fiscal se extiende hasta veinte kilómetros de la frontera, modo de lograr una mayor eficacia policíaca.

La obligada defensa de los intereses de la Corona motivó las frecuentes y continuadamente recordadas prohibiciones que en las Cortes y por cartas circulares a todos sus reinos efectuaban los monarcas castellanos, especificando la prohibición de sacar fuera de sus fronteras artículos y animales que, por su número y valor, se consideraban imprescindibles para atender las necesidades propias. 
Tres fueron los aspectos que precisaron estas medidas proteccionistas en todo tiempo: alimentación, seguridad fronteriza y metales preciosos.

Por lo que al Reino de Murcia se refiere, podemos decir que, deficitaria en cereales - con excesiva frecuencia se repiten los años de hambre- y en menor grado de vino. En el transcurso del tiempo algunas de las medidas que fueron objeto de disposiciones reales, en ocasiones se hicieron más rígidas por parte del Concejo de Murcia al afectarles directamente su falta o escasez, por lo que impidieron, con acuerdos y ordenanzas, la salida de trigo, dada su vecindad fronteriza con Aragón, por considerar que antes debían atender imprescindiblemente a otros lugares del Reino, en permanente demanda de víveres a la capital; y, caso contrario, la entrada de artículos que podían perjudicar su propia producción, tal, en ocasiones, el vino o diversas clases de telas.

También afecta al adelantamiento del reino de Murcia más que a cualquier otra parte de Castilla, la seguridad fronteriza, tanto por la permanente amenaza de ver sus tierras recorridas sin freno, en cualquier tiempo y con amplia libertad de movimiento por los almogávares granadinos, como por la vecindad aragonesa, no siempre amistosa, y el abandono litoral mediterráneo, a merced de corsarios de diversa procedencia. Hay inestabilidad fronteriza, inseguridad territorial y escasez demográfica, con grandes espacios vacíos y despoblados, que exigía abundante número de jinetes y un servicio continuo de armas y vigilancia dada la extensión del reino y el corto número de habitantes en el área rural. De aquí la prohibición de la saca de caballos y yeguas, que se extiende también a toda clase de ganados, excepto los trashumantes, y la excelencia y calidad de los equinos murcianos, repetidas veces solicitados por la realeza castellana en los siglos XIV y XV.

$\mathrm{Y}$, en tercer lugar, se precisaron las medidas proteccionistas para los metales preciosos: oro, plata, vellón y monedas de todas clases, que afectaba a todos los reinos, modo de afianzar la propia, al no corresponder su valor oficial al del metal con que estaba acuñada.

En la frontera se impone una doble fiscalización: las aduanas, que se arriendan al mejor postor y cuya actividad principal es cobrar el diezmo del almojarifazgo de todos los productos que a ella llegan; aunque con los mercaderes se establecieran cláusulas favorables para activar el comercio, como era la de no pagar en la exportación siempre que el valor de lo importado fuera de igual cuantía o moneda, pero nunca oro o plata. Alfonso $X$ al recuperar el Reino de Murcia en 1266, ya sin las limitaciones del tratado de Alcaraz de 1243 , intentó hacer desaparecer también las trabas internas, la continuidad en el cobro de roda o «rotova» por particulares, que dificultaban no sólo el comercio, sino la recuperación económica del territorio, y sustituirlas exclusivamente por las aduanas fronterizas en beneficio general y de su hacienda. No sería fácil, y la reiteración de sus cartas en este 
sentido manifiesta la continuidad, a veces secular, de algunas de ellas, como es el de La Losilla, en donde, pese a las prohibiciones reales, los comendadores santiaguistas de Ricote la mantendrían hasta fines del siglo $\mathrm{XV}^{1}$.

En carta de 28 de octubre de $1277^{2}$ dirigida a Elche, aunque tiene carácter general para todos sus reinos, Alfonso X, atendiendo la denuncia que se la había hecho contra ciertos mercaderes, a los que se acusaba de extraer oro, plata y otros metales preciosos en perjuicio de su Corona, hacía pública la prohibición existente de «sacar fuera del regno oro ni plata ni otro camio ninguno monedado ni por monedar, salvo los dineros de oro de su segnal et la moneda nueva blanca destos alfonsies que agora mande fazer desta senal misma que son los dineros del oro».

Al mismo tiempo indicaba excepciones para mercaderes y romeros del camino francés y les autorizaba a sacar hasta cincuenta sueldos de cobre prietos dos veces al año para su despensa; en cuanto a otros peregrínos sólo podían llevar consigo moneda de oro de dineros alfonsíes. Y una medida a favor del romero: que fuera creído por su juramento y por su peregrinar, salvo sospecha, porque entonces, igual que los mercaderes y cualquier otro viajero, debían ser registrados.

Otra medida proteccionista era la exención del diezmo del almojarifazgo de toda moneda de oro, plata u otro metal precioso que entrara en sus reinos. Por lo que respecta a los hombres ricos, prelados y caballeros, que quisieran marchar fuera de Castilla, debían acudir ante el rey y, caso de no poder hacerlo por lejanía, debían enviar petición justificativa de sus necesidades para poder atenderlas por escrito, advirtiendo que la falta de su autorización daría lugar al embargo de todo cuanto se intentara llevar fuera de Castilla, con premio para el acusador y apresor. Con carácter general se dispondría, tiempo más adelante, sacar, como cantidades máximas, veinte florines los caballeros y diez los pecheros.

Otras muchas vicisitudes y disposiciones en torno a las aduanas se suceden en los años siguientes, hasta que en 1488, los Reyes Católicos,

1 J.TORRES FONTES, «Puertos de La Losilla, portazgo, torre y arancel» en MMM, X, Murcia 1982, p. 57-86.

2 CODOM, III, p.152-153.

${ }^{3}$ Destaca el «proteccionismo* de Enrique III, cuando en 1403 redujo drásticamente las diecisiete aduanas con los reinos de Navarra y Aragón: 3 en Calahorra; 4 ob. de Osma; 3 en el ob. de Siguenza; 3 en el ob. de Cuenca: 3 en el obisp. de Cartagena, más su puerto, a sólo tres: Soria, Logroño y Murcia, y la maritima de Cartagena. Diecisiete que Juan II restablece en 1409. Y los itinerarios: «En la dicha çibdat de Murçia que sea el aduana, la que es mia, e que los que vinieren a la dicha aduana por la parte de Castilla, que entren por la puerta de Molina e vayan por Sant Andres e por la calle do esta el aduana de los moros, e que entren por la puerta del Açoque, e que vayas por la calle derecha que va a la Pescaderia e por la calle que va a Sant Peydro, derecho al aduana. E los que vinieren de Aragon o de la mar, que entren por la puerta de la aduana que esta en par de Sant Françisco. E los que sallieren para Aragon que salgan por 
atendiendo las quejas y solicitudes que se les hacían, dispusieron en Zaragoza, el 20 de enero de 1488 una «carta, que queremos que tenga fuerça de ley, bien asy como si estoviere asentada en los dichos nuestros quadernos de los dichos diezmos e aduanas...». En ella ordenaban a los arrendadores de diezmos y aduanas: «non demandeys ni lleveys derecho alguno ni de diezmo ni de aduana ni otra obligacion a qualesquier personas religiosa $o$ eclesiastica e seglares de qualquier ley e estado e condición que fueren e vinieren e pasaran por los dichos puertos e por cada uno dellos, por sus bestias e camas e ropas e libros e aves de caça e esclavos e otras qualesquier cosas que consygo llevaren, ni por los dineros ni monedas que llevaren para su mantenimiento e costas, ni les demandeys ni apremieys a que se escrivan en las nuestras casas de aduana ni otras partes algunas, aunque non vos muestren nuestras cartas e mandamientos, jurando que lo que ansy llevaren e traxeren non es mercadoria suya ni de otra personas alguna e que no lleva otra cosa alguna encobierta de moneda ni de mercadorias ${ }^{4}$.

El panorama peninsular en 1493 se presenta con variado y dilatado horizonte. En los comienzos del año anterior había finalizado la guerra de Granada, y este hecho y la unión matrimonial de Fernando e Isabel, aunque se mantuvieran diferenciadas ambas coronas en cuanto a la cuidadosa vigilancia de sus comunes fronteras en el orden político, administrativo y económico, iban a proporcionar una novedad trascendente para el adelantamiento murciano, cual era la seguridad, la desaparición de la permanente amenaza medieval de ser cautivado o robado en cualquier momento o lugar de su territorio. Seguridad que permitiría transitar en todas direcciones, que impulsaría la multiplicación del comercio y que facilitaría el intercambio de productos, de ideas, modas y habitación. Crece entonces la producción artesanal al mismo ritmo que las cada vez mayores necesidades y se reanudan cultivos en tierras abandonadas y yermas durante más de dos siglos. Prosperidad, elevación del nivel de vida y la persistencia de un gobierno enérgico que, más que innovador, hay que calificar como exigente en el cumplimiento de pragmáticas, leyes y ordenanzas, hace que la monarquía autoritaria de los Reyes Católicos no sólo alcance un bien ganado prestigio que se extiende más allá de la frontera pirenaica o por el Mediterráneo, sino que su política centralizadora lleva consigo el intervencionismo real por la doble vía de los corregidores, controlando directamente la vida ciudadana, y indirectamente la de resolver todos los demás asuntos en

la dicha puerta por donde han de entrar, e que no puedan entrar ni sallir por otra parte... $\rightarrow Y$ lo mismo señala como único camino a seguir: eLos que vinieren del dicho regno de Aragon o por Aragon al aduana de Murçia, que entren e salgan por el camino de allende el agua, que va por Benihel.» Tema de las aduanas murcianas sobre las que habremos de volver con mayor detenimiento.

${ }^{4}$ AMM Cart. 1478-88, fol. 213. 
su Corte, lo que obliga y resulta forzoso, pues así lo exige la norma, a viajar tras la andariega Corte real, tanto a los procuradores y representantes concejiles o señoriales, como de quienes con carácter más personal tenían que resolver sus pretensiones o reivindicaciones ante el consejo real.

Todo ello ocasiona, entre otras muchas cosas, un intenso tráfico, que, merced a la pacificación del territorio y eficaz persecución de los malhechores, se efectúa con mayor rapidez y facilidad que muy pocos años antes. Y se viaja por múltiples causas, incluso una que, sin ser novedad primeriza, adquiere carácter más indefinido que las concretamente medievales del peregrinar, comerciar o las del entretejer diplomático, y es viajar por puro capricho, por el placer de ver, conocer, tratar, aprender y convivir en tierras y con gentes extrañas. Hay un sólo obstáculo: las dificultades fronterizas que afectan al viajero, al mercader, al peregrino, al emisario, a todo aquél que quiera salir o entrar por las fronteras castellanas, que se les pone en las aduanas.

Un relato muy cercano cronológicamente, que refleja estos condicionamientos, y precisamente en la frontera murciano-valenciana, lo encontramos en las memorias de Antonio de Lalaing, quien el sábado 1 de octubre de 1501 llegaba a «un pueblo grande llamado Yecla, donde a media legua se hace la separación del reino de España y del reino de Valencia, que es del rey de Aragón», y más adelante añade: «es costumbre en España que, al salir del reino para entrar en otro país, los viajeros, sean caballeros o mercaderes, incluso aquéllos de la casa del rey, se vean obligados a pagar la décima parte de su dinero, sortijas, vestidos y otras cosas que llevan fuera de dicho país, salvo el dinero de su gasto y los vestidos de su cuerpo, si no llevan carta del rey y de la reina ordenando a los recaudadores de dichos dineros que les dejen pasar libremente». $\mathrm{Y}$ agrega la advertencia de que si «alguno pasaba sin hablar con los recaudadores para hacer fraude de su derecho, todo lo que llevase sobre él sería confiscado para el rey y la reinas ${ }^{3}$.

En la ciudad, el cambio de corregidor suponía algo más que la simple sustitución de su funcionario real por otro. La mentalidad, formación jurfdica, experiencia, dotes personales, hombres a su servicio, lugar y tiempo en que se produce el cambio modifican a veces profundamente el gobierno de la ciudad. Es unas veces porque presta mayor atención a determinadas cosas y olvida otras; lo es por introducir novedades o posibilitar otras actividades, o simplemente, por ser más exigente en el cumplimiento de su oficio y obligación. Y en este aspecto destaca el licenciado Pedro Gómez de Setúbar, que nada más tomar posesión de su corregimiento el 25 de mayo de 1493, comenzó a imponer nuevas normas y a preocuparse de asuntos que

${ }^{5}$ Lalaing, Antonio, Sr. de Montigny, en GarCin MrrCadal, Viajes de extranjeros por España y Portugal, Madrid 1952, p. 476. 
hasta entonces habían quedado olvidados o no habían llamado la atención de sus antecesores. Y una de éstas iba a ser recoger en relación cronológica cuantas personas pasaban por la aduana, con indicación de su nombre, procedencia, motivo del viaje, acompañantes, animales que llevaba consigo $\mathrm{y}$ dinero o alhajas de que eran portadores, especificando en ocasiones el destino del numerario, aparte del permitido para su manutención. Porque al viajero, cualquiera que fuera su condición social, oficio, procedencia y destino, estado, etc., debía justificar documentalmente cuanto llevaba para impedir fraudes o su pérdida. Y la manifestación de dineros se hacía públicamente en solicitud del albalá-pasaporte ${ }^{6}$.

Por orden de Pedro Gómez de Setúbar en diciembre de 1495 se recogieron «las manifestaciones de los dineros que se han dado alvalaes para llevar dineros a Aragon para costa y mantenimiento». De esta relación de viajeros que llegan a Murcia, para seguir, vía Orihuela, camino de Aragón, recogemos los correspondientes al año concejil que comenzó el 24 de junio de 1493 y terminó en igual fecha del año siguiente por su mayor amplitud y por las circunstancias especiales que concurren en él, debido a la larga estancia de los Reyes Católicos en Barcelona y reciente conquista del reino de Granada, lo que sin duda influiría en la mayor afluencia de viajeros por Murcia con dirección a la ciudad catalana. Suman un total superior a noventa personas, que se agrupan en cincuenta anotaciones, a los cuales se les extiende el correspondiente albalá justificativo de las cantidades que portaban, su destino y, en su caso, autorización para ello. De esta cantidad dos tercios realizan su viaje en el segundo semestre de 1493, lo que sin duda, como queda indicado, se debe a la permanencia de la Corte real en Barcelona desde junio a septiembre, y en Zaragoza los meses de noviembre y diciembre. El traslado de la Corte a Castilla en enero de 1494 obligaría a un cambio de ruta para quienes acudían a despachar asuntos oficiales, lo que hizo disminuir el número de viajeros que pasaban por Murcia camino de Aragón, si bien dentro de esta limitación es posible apreciar una mayor afluencia de transeúntes en el mes de febrero, ya que suman siete, aunque ninguno de ellos sea indicativo del motivo del viaje en esta fecha.

${ }^{6} \mathrm{La}$ novedad que introduce Gómez de Setúbar es la de recoger cronológicamente los albalaes dados a cuantos manifestaron dincros a su paso por Murcia en el tiempo en que él fue corregidor. Años antes, ś6lo espaciadamente se relacionan en las actas capitulares algunos de ellos, como en noviembre de 1488: Simón y Pedro, criados del conde de Trevento, con 50 reales uno y con 2 ducados, 1 dobla castellana, medio castellano, un florín de oro, media dobla morisca y un real el otro; Gonzalo de Aguilar, criado de Hernando de Zafra, secretario de los Reyes Católicos, pasaba a Aragón para comprar ciertas cosas y provisiones para su señor, con 64 eruzados, 3 doblas, 1 castellano, medio florín y 23 reales y medio. Mes y medio más tarde, era el célebre Bernal Francés, quien declaraba a su paso por Murcia 2 doblas, 2 florines y 28 reales castellanos, en tanto que un compañero de viaje declaraba 3 ducados, 1 dobla castellana y 14 reales castellanos. La variedad monetaria seguía síendo amplia y, sin duda, produciendo buenos ingresos a los agentes oficiales de cambio, pero también a los que no tenian tal tínlo. 
Variedad de viajeros: cabe singularizar a peregrinos que van a Jerusalem, Roma, Santiago y Montserrat. Por su origen: dos venecianos, cuatro genoveses, dos franceses, tres napolitanos, dos sicilianos, dos granadinos, un romano, un moro de Elche, mallorquines, valencianos, etc., y de distintos puntos de Castilla, incluso de Jerez. Frente a esta variedad de origen, contrasta la escasez en la mención de oficios, si bien cabe deducir que en su mayor parte los extranjeros eran mercaderes o relacionados con el mundo del dinero; tres clérigos, un castrador de bestias, un fundidor; dos boneteros; mensajeros del Condestable, del señor de Portocarrero, de Luis de Santángel, conde de Tendilla, moros de Granada, todos hacia la Corte, así como los relacionados con la justicia, pues la danza y contradanza de los pleitos ante el consejo real y chancillería no había hecho nada más que comenzar.

Resulta también curioso la variedad de moneda que todavía se utiliza y con la que se viaja -quizá aún más que en la etapa medieval-: carlines, reales castellanos y medio reales, reales italianos y medios reales, florines de oro, coronas de oro, ducados de oro y plata y medios ducados, castellanos de oro, cruzados de oro, medios castellanos, "piezas de oro», doblas castellanas y moriscas, tasis, quilates, maravedís, tazas de plata, dinero menudo, etc. Son los alemanes quienes portan coronas, quilates y carlines; en tanto que los sicilianos llevan castellanos, ducados, justos y dineros; $y$, por su oficio, el fundidor maestre Lope, llamado por los Reyes a Barcelona, portaba dieciséis piezas de oro y una taza de plata. Y todos con diversidad de moneda: Juan de Salamanca y su hijo Juan, con un macho de silla, portan un ducado, una dobla, medio castellano, diecinueve reales castellanos. Los sicilianos Angelo Tribullita y Antonio Rofino llevan dos mozos, dos mulas, un macho, cuatro castellanos, tres ducados, medio ducado, un justo y cuatro dineros.

No se contabilizan los animales que llevan, bien porque no se indican o se hace el indeterminado de "cabalgaduras», a veces sin numerar, lo que impide establecer o deducir de forma más concreta cuál era su porcentaje, toda vez que la mención de caballos y mulas parece indicar cabalgaduras, ya que se señala a veces que son de silla; más indeterminado es el mulo, unas veces de silla y otras de carga, como el asno. También cuenta la posición social de estos viajeros: los genoveses llevan mozos y mulas; dos venecianos, seis cabalgaduras y sus personas, y sus mozos; un caballero, el único que se menciona con este tratamiento, es Alonso de Luco, que bien pudiera ser Alonso Fernández de Lugo, el conquistador de las Canarias, que marchaba a Barcelona a presentarse ante los Reyes. Su paso por Murcia fue el 17 de octubre de 1493, llevando consigo, como trofeos, parte del botín conseguido y algunos indígenas. La escueta referencia concejil no distingue de razas y se limita a decir que le acompañaban «cierta gente e cabalgaduras». Cuentan también los peregrinos a Jerusalem, que viajan con dos 
mozos y dos mulos, pero que son superados por los sicilianos, con dos mozos, dos mulas y un macho. Y por Cristóbal Guirle, con cuatro caballos y la gente que los llevaba.

A la vuelta de su primer viaje, llamado por los Reyes a Barcelona, Cristóbal Colón efectúa un viaje triunfal, llevando consigo amplio muestrario de tierras americanas: oro, carátulas, papagayos e indios. Viajó por tierra y en el mes de abril de 1493, como señala Morales Padrón, pasaba por Murcia, con lo que repetía su anterior estancia (de predescubrimiento), en 1488. Pero al frente del concejo no se hallaba todavía Pedro Gómez de Setúbar, que comenzó su gestión el 23 de junio siguiente, esto es, dos meses después del paso de Colón. El bachiller Antón Martínez de Aguilera, su antecesor, no tuvo la meticulosidad de ir relacionando a cuantos pasaban por la aduana de Murcia hacia Aragón y les firmaba albalaes del dinero que manifestaban. Por sólo dos meses nos quedamos sin ese testimonio documental del paso de Colón por Murcia, del que tampoco queda reflejo alguno, por cualquier otro motivo; en las actas del concejo murciano.

Al año siguiente, el 14 de octubre de 1494, procedentes de Orihuela, entraba en Murcia el viajero alemán Gerónimo Münzer. Tras visitar la Catedral y elogiar la ciudad, comparándola con Nuremberg, siguió adelante hacia Granada, sin dejar más huella de su paso que sus memorias. Y no se menciona en las actas capitulares porque la minuciosa relación de Pedro Gómez de Setúbar se refiere tan sólo, exclusivamente, a los viajeros que pasaban la aduana de Murcia camino de Aragón y allí manifestaban cuanto llevaban, para que se les diera albalá justificativo. 


\section{APÉNDICE}

«Manifestaciones de los dineros que se han dado albalaes para llevar dineros a Aragon para costa y mantenimiento de lo que han llevado despues que el licenciado Pedro Gomez de Setubar es corregidor de la muy noble ciudad de Murçia, que fue reçibido a veinte e çinco dias del mes de mayo, año de mill e quatroçientos e noventa e tres.. (AMM, Actas Capitulares, 1495)

1493-VII-1. Un hombre boltojador (?) lleva para su gasto y de otro compañero, con dos mozos y dos mulas, y que va en romería a Sepulcro Santo de Jerusalem, veintitres piezas de oro diversas. Juran que en la manifestación no hubo fraude, colusión ni encubierta alguna. Conforme a la disposición de Alfonso $\mathrm{X}$ fueron créidos por sus juramentos y no registrados. Le fue dado albalá firmado por el señor corregidor.

1493-VII-4. Pedro de Moya, vecino de Cuenca. Marcha a Aragón con mil maravedís.

1493-VII-5. Maestre Francisco Campanero, de nación napolitana, que venía de romería de Señor Santiago e iba para su tierra. Veinticuatro reales castellanos.

1493-VII-11. Juan de Picardía. Marcha a Aragón y manifiesta un cruzado, de oro, dos reales y diecisiete dineros.

1493-VII-13. Pedro de Baena, marcha a Barcelona con cartas para la Corte. Lleva tres cruzados de oro, un florín y seis reales.

1493-VII-21. Miguel Navarro. Se dirige a alas partes de Aragón y lleva un ducado de oro.

1493-VII-24. Luis Navarro, se dirige a la Corte real en Barcelona con cartas del Conde de Tendilla. Declara diecinueve reales castellanos y treinta y cinco dineros.

1493-VII-25. Antonio Muñoz. Se dirige a Barcelona, a la Corte de los Reyes Católicos y procede de Granada, portando cartas del condestable. Manifiesta dos doblas castellanas, cuatro ducados, cuatro reales y en menudo tres reales.

1493-VII-25. Alonso de Jaén, del reino de Valencia, y Juan de Cota y Gabriel Linas, de Mallorca. Marchan a Aragón y llevan dos mil quinientos maravedís.

1493-VIII-2. Miguel de Leza. Se encamina a Barcelona a la Corte. Declara un castellano, un ducado y veinte maravedís.

1493-VIII-5. Dos hombres pobres, que se dirigen a Aragón en romería, a Santa Maria de Monserrat. Dos reales y seis dineros uno; y diecisiete reales y medio, el otro.

1493-VIII-8. Juan Piñar, vecino de Lorca. Va a Barcelona a la Corte real en seguimiento de un pleito, con cinco mil quinientos maravedís.

1493-VIII-10. Pablo Dellon, clérigo, en dirección a Roma. Manifiesta doce ducados de oro, seis reales italianos y dos reales castellanos.

1493-VIII-13. Lope de Molina, vecino de Lorca, con un mozo, un caballo y un asno. Veintidós reales castellanos. 
1493-VIII-15. Teri Abuteares. Marcha a Alemania y porta una corona de oro, medio carlín y veintitrés quilates.

1493-VIII-26. Miguel de Alfaro. Con dos castellanos y cinco reales.

1493-VIII-27. Juan Carmer, de nación francesa, se dirige a Valencia. Manifiesta dos castellanos y dos reales.

1493-VIII-27. Hernando de Villena, clérigo. Marcha a la Corte real por negocios tocantes a la Iglesia de Cartagena, con un mozo, una mula y once mil maravedís.

1493-VIII-28. Juan de Santander. Se dirige a Barcelona, a la Corte real con cartas del señor de Portocarrero. $Y$ declara un castellano, medio castellano y dos reales.

1493-VIII-28. Hamet Omar y Mahomad Omar, proceden de Granada y se dirigen a Barcelona a librar cientas cosas de la ciudad de Granada con los Reyes. Siete ducados de oro y plata.

1493-IX-3. Martín de Cáliz, vecino de Toledo. A Aragón con un florín, medio ducado y siete reales.

1493-IX-20. Gonzalo de Jerez, vecino de Jerez, en dirección a Barcelona, va a tratar asuntos en la Corte. Siete castellanos, dos doblas y doce reales.

1493-IX-24 Cristóbal Romano, vecino de Roma, marcha a ella con siete ducados y medio.

1493-X-14. Hombre que dijo ser maestre Lope, fundidor, que va por mandado de sus Altezas a la Corte, según mostró por cédula real. Pasa a Aragón con dieciséis piezas de oro $y$ una taza de plata.

1493-X-17. Maestre Andrea y Antonio, vecinos de Nápoles, van a Aragón. Llevan dos ducados, un castellano, diez reales de diversas monedas y seis reales en menudo.

1493-X-17. Un caballero, Alfonso de Luco, que va a la Corte real con cierta gente en cabalgaduras. Veintiún castellanos de oro.

1493-X-20. Cristóbal Guirle. Marcha a Aragón con cuatro caballos y la gente que los lleva. Con veintidós ducados.

1493-X-20. Rodrigo Muntañes. A Roma, con tres ducados y diez reales castellanos.

1493-XI-10. Bernabé de Negro, Juan Antonio de Negro, Lucas Justiniano, Agustín de Negro, todos genoveses que se encaminan a Aragón. Con ellos mozos y cabalgaduras. Diez ducados de oro.

1493-XI-16. Martín de Córdoba, se dirige a Aragón con un hombre y un macho. Porta tres doblas, un ducado y trescientos maravedís en moneda menuda.

1493-XI-23. Juan de Yepes. Se dirige a Aragón con doce reales y un ducado.

1493-XII-18. Un moro de la villa de Elche. Marcha a Aragón con treinta y cuatro reales castellanos.

1494-[-20. Un francés que va a Francia, su tierra. Lleva veintiséis reales en plata y en menudo.

1492-I-22. Fernando de Sasido. Va a Aragón con doce reales.

1494-I-29. Pedro Nynfil y Benito de Alfin, venecianos. Se dirigen a Aragón, con seis cabalgaduras y sus personas. Declaran veinte ducados. 
1494-II-4. Juan Farnés. Se encamina a Aragón y declara siete piezas de oro.

1494-II-4. Juan Carrillo. Marcha a Aragón con siete piezas de oro.

1494-II-11. Juan de Cazorla y Bernardo de Vitoria. Marcha a Aragón, uno con cuatro reales y otro con siete castellanos y diez reales.

1494-II-14. Un pobre que venía de romería de Santiago de Compostela. Treinta reales en moneda de oro y de menudos.

1494-II-17. Alfonso Barafuzanero. Va a Aragón con treinta reales castellanos.

1494-II-19. Un hombre castrador de bestias. A Aragón, con dieciséis reales en plata y en menudos.

1494-II-26. Lorenzo Bezita, clérigo presbítero del Reino de Aragón. Marcha con otro compañero y dos mulas. Llevan dos castellanos de oro y diez reales en limosna.

1494-III-3. Francisco Berenguer clérigo, Un mozo y un macho hacia Valencia. Declara cinco doblas, dos ducados y doce reales castellanos.

1494-III-27. Juanoto Limiñana, vecino de Orihuela. Marcha a la Corte por el pleito que trata en nombre de Luis de Santágel y lleva veinte ducados.

1494-IV-7. Diego de Morales y Domingo Ferrández, boneteros, con cincuenta y tres reales castellanos.

1494-IV-9. Juan de Salamanca y Juan de Salamanca su hijo. A Barcelona con un macho de silla, un ducado, una dobla, medio castellano, un castellano y diecinueve reales castellanos.

1494-IV-13. Pedro Sánchez Román, vecino de Almería, con un mozo y una mula. Se dirige a Barcelona y declara un castellano, medio castellano, medio ducado y cinco reales.

1494-VI-23. Angelo Tribullita y Antonio Rofino, sicilianos. Al reino de Sicilia con dos mozos, dos mulas, un macho, cuatro castellanos, tres ducados, medio ducado, un justo y cuatro dineros. 